\title{
Manejo da irrigação do meloeiro com base na evaporação do tanque classe A
}

\author{
Wellington F Araújo; Gabriela A Oliveira; Fátima K de Carvalho; Washington M da Silva; Pablo LS \\ Cruz; Francisco Clemilto da S Maciel \\ UFRR-CCA, Av. Enê Garcez, 2413, Aeroporto, 69304-000 Boa Vista-RR; wellingtonufrr@gmail.com
}

\section{RESUMO}

O objetivo do trabalho foi avaliar o efeito de diferentes níveis de irrigação, com base em frações da evaporação do tanque classe A (ECA) sobre a produtividade, características químicas (teor de sólidos solúveis e $\mathrm{pH}$ ) e físicas (massa, diâmetro do fruto e firmeza da polpa) do melão cultivar Bônus $n^{\circ} 2$ cultivado em ambiente protegido irrigado por gotejamento, no estado de Roraima. O delineamento experimental foi de blocos ao acaso, contendo seis tratamentos $(0,20 ; 0,40$; 0,$60 ; 0,80 ; 1,00$ e $1,20 \%$ do ECA) e quatro repetições. Houve uma relação linear crescente da produtividade de frutos com o aumento dos níveis de irrigação, apresentando valores máximo de $4 \mathrm{~kg} \mathrm{~m}^{-2}$. As características físicas, exceto firmeza de polpa, elevaram-se com o aumento das lâminas de irrigação. O teor de sólidos solúveis foi influenciado pelas lâminas de irrigação, resultando em efeito linear decrescente, com valores variando de 10,4 a $11,7^{\circ}$ Brix, enquanto $\mathrm{o} \mathrm{pH}$ do fruto não foi influenciado pelos tratamentos, apresentando média de 6,74 .

Palavras-chave: Cucumis melo L., ambiente protegido, melão, Roraima.

\begin{abstract}
Irrigation management of muskmelon using the class A pan evaporation

An experiment was carried out to evaluate the effects of irrigation levels, based on fractions of the class A pan evaporation, on yield and the chemical and physical characteristics of muskmelon cultivar Bonus $\mathrm{n}^{\circ} 2$ grown under plastic house conditions and drip irrigation in Roraima State, Brazil. The experimental design was randomized blocks with six treatments $(0.20 ; 0.40 ; 0.60 ; 0.80 ; 1.00$ and $1.20 \%$ of ECA) and four replications. The results of yield showed a linear response of the applied irrigation levels, with values of $4 \mathrm{~kg} \mathrm{~m}^{-2}$. All others physical characteristics, except for pulp firmness, showed a linear response to irrigation treatments. Total soluble solids showed a linear decreasing response with respect to the irrigation levels with values between 10.4 and $11.7^{\circ}$ Brix, while fruit $\mathrm{pH}$ was not affected by treatments, averaging 6.74 .
\end{abstract}

Keywords: Cucumis melo, greenhouse, melon, Roraima State.

\section{(Recebido para publicação em 9 de abril de 2009; aceito em 13 de outubro de 2010) (Received on April 9, 2009; accepted on October 13, 2010)}

$\mathrm{O}$ s frutos do meloeiro (Cucumis melo L.) são apreciados no Brasil. São boa fonte das vitaminas A, B, B2, B5 e $\mathrm{C}$; de sais minerais como potássio, sódio e fósforo, e possuem valor energético baixo (20 a $62 \mathrm{kcal} / 100 \mathrm{~g}$ de polpa). Dentre os diferentes tipos de frutos do meloeiro, o melão rendilhado (Cucumis melo var. reticulatus Naud.), do grupo Reticulatus, de formato redondo-ovalado, aroma marcante, teor de sólidos solúveis ao redor de $10^{\circ}$ Brix e cor da polpa variando de verde-claro a salmão, vem se destacando pelo sabor e aspecto visual, que o diferencia dos outros tipos existentes no mercado (Silva \& Costa, 2003).

Segundo Brandão Filho \& Vasconcellos (1998), o melão rendilhado pode ser cultivado em ambiente protegido, sendo possível o cultivo em duas ou três épocas do ano, possibilitando produtividades entre 1,8 e 3 frutos $\mathrm{m}^{-2}$ em casa de vegetação.

A produtividade e a qualidade dos frutos do meloeiro podem ser influenciadas por fatores como nutrição mineral (Coelho et al., 2003), umidade do solo (Costa et al., 2002; Monteiro, 2004; Koetz et al., 2006 ; Dogan et al., 2008; Siqueira et al., 2009), condições ambientais (Rizzo \& Braz, 2001; Koetz et al., 2006) e época de colheita (Bleinroth, 1994).

A firmeza da polpa é um dos principais atributos de qualidade em frutos. Suas propriedades mecânicas de resistência dos tecidos se correlacionam com as características estruturais das células, encontrando-se trabalhos na literatura que avaliam sua alteração durante o processo de armazenamento de frutos e hortaliças (Menezes et al., 1998, 2001).

Quanto a resposta do meloeiro à irrigação, Coelho (1978), aplicando lâminas de água por gotejamento na cultura do melão, obteve maior produção com lâminas equivalentes a 75 e 100\% da evaporação do tanque classe $\mathrm{A}$, com intervalos de irrigação de 2 dias. Koetz et al. (2006) trabalharam com diferentes níveis de irrigação e freqüência de adubação em melão cultivado em ambiente protegido e não observaram diferenças significativas na produção e qualidade do fruto, exceto para o teor de sólidos solúveis. Siqueira et al. (2009) trabalharam em cultivo protegido e irrigação por gotejamento com freqüência de dois dias em melão amarelo 'Vereda' e obtiveram efeito na espessura da polpa, acidez total titulável e teor de sólidos solúveis que reduziram com o aumento das lâminas de irrigação.

O objetivo do presente trabalho foi avaliar a produtividade e a qualidade dos frutos de melão rendilhado em função de diferentes níveis de irrigação, cultivado 
em ambiente protegido em Roraima.

\section{MATERIAL E MÉTODOS}

O experimento foi conduzido em ambiente protegido localizado na área experimental do CCA da Universidade Federal de Roraima, em Boa Vista-RR (2'42'30'”N, 47³8'00'”W e $90 \mathrm{~m}$ de altitude). $\mathrm{O}$ ambiente protegido utilizado era do tipo capela, com $7 \mathrm{~m}$ de largura e $40 \mathrm{~m}$ de comprimento, com estrutura de madeira nas colunas de sustentação, altura na parte central de $4,6 \mathrm{~m}$ e pé direito de $3,0 \mathrm{~m}$. A parte superior foi coberta por filme de polietileno transparente de alta densidade (PEAD), com aditivo ultravioleta e espessura de $150 \mathrm{~mm}$, e as laterais foram fechadas com tela de proteção de cor preta.

O solo é classificado como Latossolo Amarelo e tem, em média, $71 \%$ de areia, $6 \%$ de silte e $23 \%$ de argila, para o perfil de 0 a $20 \mathrm{~cm}$ de profundidade. As características químicas são: $\mathrm{pH}$ (água) $=4,9$; $\mathrm{Ca}=0,21 \mathrm{cmol}_{\mathrm{c}} \mathrm{dm}^{-3} ; \mathrm{Mg}=0,68 \mathrm{cmol}_{\mathrm{c}}$ $\mathrm{dm}^{-3} ; \mathrm{K}=0,10 \mathrm{cmol}_{\mathrm{c}} \mathrm{dm}^{-3} ; \mathrm{Al}=0,32$ $\mathrm{cmol}_{\mathrm{c}} \mathrm{dm}^{-3} ;(\mathrm{H}+\mathrm{Al})=2,72 \mathrm{cmol}_{\mathrm{c}} \mathrm{dm}^{-3}$; $\mathrm{P}=6,31 \mathrm{mg} \mathrm{dm}^{-3}$; $\mathrm{SB}$ ( $1,09 \mathrm{cmol}_{\mathrm{c}} \mathrm{dm}^{-3} ; \mathrm{CTC}=3,8 \mathrm{cmol}_{\mathrm{c}} \mathrm{dm}^{-3}$. A partir dos resultados da análise química do solo e seguindo recomendações propostas por Raij et al. (1997) para a cultura do meloeiro, foram aplicados e incorporados ao solo $100 \mathrm{~g} \mathrm{~m}^{-2}$ de calcário dolomítico e $2 \mathrm{~kg} \mathrm{~m}^{-2}$ de esterco de gado curtido. Após nivelamento do solo, foram levantados canteiros de $20 \mathrm{~cm}$ de altura, deixando-se $20 \mathrm{~cm}$ de área livre entre os mesmos. Foram abertas covas de $25 \mathrm{~cm}$ de profundidade, nas quais foram aplicados $10 \mathrm{~g}$ de FTE-BR 12, 17 $\mathrm{g}$ de uréia, $40 \mathrm{~g}$ de cloreto de potássio e $160 \mathrm{~g}$ de superfosfato simples.

Os tratamentos consistiram da aplicação diária de lâminas de água, definidas com base em frações da água evaporada pelo tanque classe A (ECA) 0,$2 ; 0,4 ; 0,6 ; 0,8 ; 1,0$ e $1,2 \%$ do ECA. $\mathrm{O}$ delineamento estatístico adotado foi de blocos ao acaso com seis tratamentos e quatro repetições, totalizando 24 parcelas.

Sementes de melão (Cucumis melo L.), do tipo rendilhado, cultivar Bônus $\mathrm{n}^{\circ} 2$ foram semeadas em substrato comercial (Plantimax $\left.{ }^{\circledR}\right)$, em bandejas de poliestireno de 100 células, e, aos 20 dias após a germinação, as plantas foram transplantadas para o local definitivo, no espaçamento de $0,5 \mathrm{~m}$ entre plantas e 1 $\mathrm{m}$ entre linhas. A parcela experimental possuía 3,5 $\mathrm{m}$ de comprimento e 80 $\mathrm{cm}$ de largura, contendo, assim, uma linha de sete plantas, sendo consideradas como parcela útil as cinco plantas centrais.

Do transplantio até o $30^{\circ}$ dia, quando os tratamentos foram iniciados, todas as plantas foram irrigadas da mesma forma, repondo-se a lâmina de água correspondente à água evaporada de um tanque classe A inserido dentro do ambiente protegido. Os tratos culturais e controle fitossanitário foram executados em função das necessidades da cultura.

Cinco fertirrigações foram realizadas, em intervalos semanais, a partir do $30^{\circ}$ DAT (dias após o transplante), nas quais aplicou-se uréia e cloreto de potássio, nas doses de 400 e 200 g por cada fertirrigação, respectivamente. Para realizar este procedimento, os fertilizantes foram pesados separadamente, misturados, diluídos em balde de $20 \mathrm{~L}$ de água e injetados ao sistema, via tubo Venturi, durante as irrigações.

Utilizou-se sistema de irrigação localizado por gotejamento, com emissores espaçados a $30 \mathrm{~cm}$ e vazão nominal de $1,13 \mathrm{~L} \mathrm{~h}^{-1}$. Visando verificar as condições hídricas do solo em cada tratamento, tensiômetros foram instalados, em uma parcela de cada tratamento, a $15 \mathrm{~cm}$ de profundidade e com distância radial de $10 \mathrm{~cm}$ de um emissor. Aos 7 DAT um termohigrômetro foi instalado no interior do ambiente protegido, para registros diários dos valores máximo e mínimo referentes à temperatura e umidade relativa do ar.

O sistema de condução das plantas foi aquele recomendado por Gualberto et al. (2001), no qual são deixadas duas hastes por planta, e um fruto por haste, visando obter frutos com peso médio ideal para a comercialização, com a maior produtividade física possível.

O tutoramento das plantas foi feito com fitilhos plásticos presos a dois arames lisos colocados a 0,7 e 2,0 m de altura. Os brotos laterais em excesso foram eliminados e feita a capação do broto apical, quando este atingia o arame superior. A fim de auxiliar a sustentação dos frutos pelas plantas e evitar ruptura dos seus pedúnculos, estes foram acondicionados em cestas plásticas (enredados) presas às linhas de arame.

A colheita dos frutos iniciou-se aos 83 DAT, quando os frutos atingiram o ponto de maturação fisiológica, ou seja, rendilhamento completo em volta do pedúnculo, e estendeu-se por uma semana. Foram amostrados quatro frutos por parcela e nestes foram analisadas as variáveis teor de sólidos solúveis totais, pH e firmeza de polpa. Para análise de produção, os frutos de cada planta, dentro da área útil de cada parcela, foram coletados, levados ao laboratório e medidos individualmente, sendo os dados contabilizados em massa fresca $(\mathrm{kg})$ e produtividade $\left(\mathrm{kg} \mathrm{m}^{-2}\right)$, considerando a densidade de 20.000 plantas ha ${ }^{-1}$, ou seja, 2 plantas $\mathrm{m}^{-2}$.

Para determinação do $\mathrm{pH}$, o fruto foi cortado e parte da polpa foi homogeneizada em um liquidificador, procedendose a retirada do sobrenadante para leitura do $\mathrm{pH}$, feito com o pHgâmetro de mesa. O teor de sólidos solúveis foi avaliado utilizando-se um refratômetro digital de bolso (resolução de 0,2 ), sendo os valores expressos em ${ }^{\circ}$ Brix e corrigidos para $20^{\circ} \mathrm{C}$. Para avaliação da firmeza da polpa, o fruto foi dividido longitudinalmente em duas partes, sendo que em cada uma das metades foram realizadas duas leituras (na região equatorial do fruto) usando-se penetrômetro manual Mc Cormick modelo FT 327 com ponteira cilíndrica de $8 \mathrm{~mm}$ de diâmetro. Os resultados obtidos em libra (Lbf) foram posteriormente expressos em Newton (N) utilizando-se o fator de conversão 4,445.

Os dados obtidos foram interpretados por meio das análises de variância e de regressão, considerando o teste $\mathrm{F}$ a $5 \%$ de probabilidade.

\section{RESULTADOS E DISCUSSÃO}

A temperatura do ar variou de 36,4 (média das máximas) a $24^{\circ} \mathrm{C}$ (média das mínimas), enquanto a umidade relativa média foi de 54,5\%. A lâmina evaporada variou de 2,9 a 7,2 $\mathrm{mm} \mathrm{dia}^{-1}$.

As lâminas de irrigação utilizadas 
Tabela 1. Lâminas de Irrigação $(\mathrm{mm})$ aplicadas em cada tratamento para o cultivo de melão cv. Bônus $\mathrm{n}^{\circ} 2$ em ambiente protegido e valores de potencial mátrico $(-\mathrm{kPa})$ médio a $15 \mathrm{~cm}$ de profundidade (irrigation levels $(\mathrm{mm})$ for muskmelon cultivar Bonus $\mathrm{n}^{\circ} 2$ grown under plastic house conditions and matric potential (-kPa) at $15 \mathrm{~cm}$ depth). Boa Vista-RR, UFRR, 2008.

\begin{tabular}{crrrrrr}
\hline Tratamentos & \multicolumn{5}{c}{ Lâminas (mm) } & Pot. Mátrico \\
\cline { 2 - 5 } (\% de ECA) & Fev & Mar & \multicolumn{1}{c}{ Abr } & Mai & Total & (-kPa) \\
\hline 20 & 36,2 & 93,3 & 22,9 & 9,2 & 161,6 & 52,3 \\
40 & 36,2 & 103,7 & 45,9 & 18,3 & 204,2 & 38,3 \\
60 & 36,2 & 114,2 & 68,8 & 27,5 & 246,8 & 28,2 \\
80 & 36,2 & 124,7 & 91,8 & 36,7 & 289,4 & 42,7 \\
100 & 36,2 & 135,2 & 114,7 & 45,9 & 331,9 & 10,0 \\
120 & 36,2 & 145,6 & 137,6 & 55,0 & 374,5 & 21,1 \\
\hline
\end{tabular}

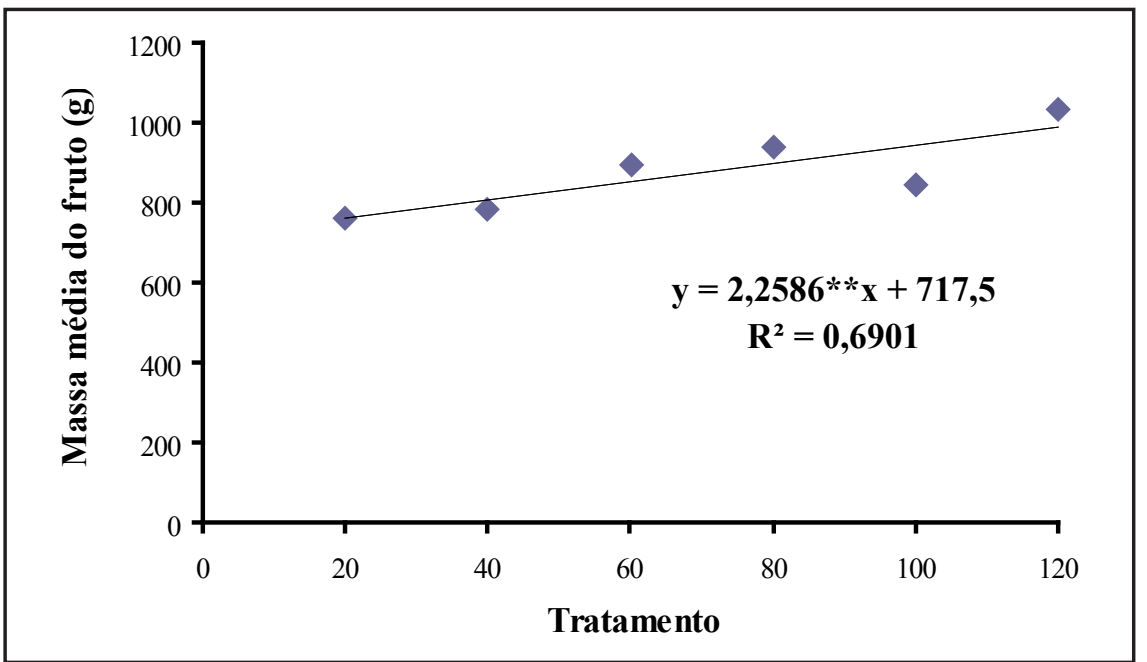

Figura 1. Massa média do fruto (g) de melão cv. Bônus $\mathrm{n}^{\circ}$ 2, cultivado em ambiente protegido em função das lâminas de irrigação (commercial weight per plant (g) of muskmelon cultivar Bonus $\mathrm{n}^{\circ} 2$ grown under plastic house conditions as a function of irrigations levels). Boa Vista-RR, UFRR, 2008.

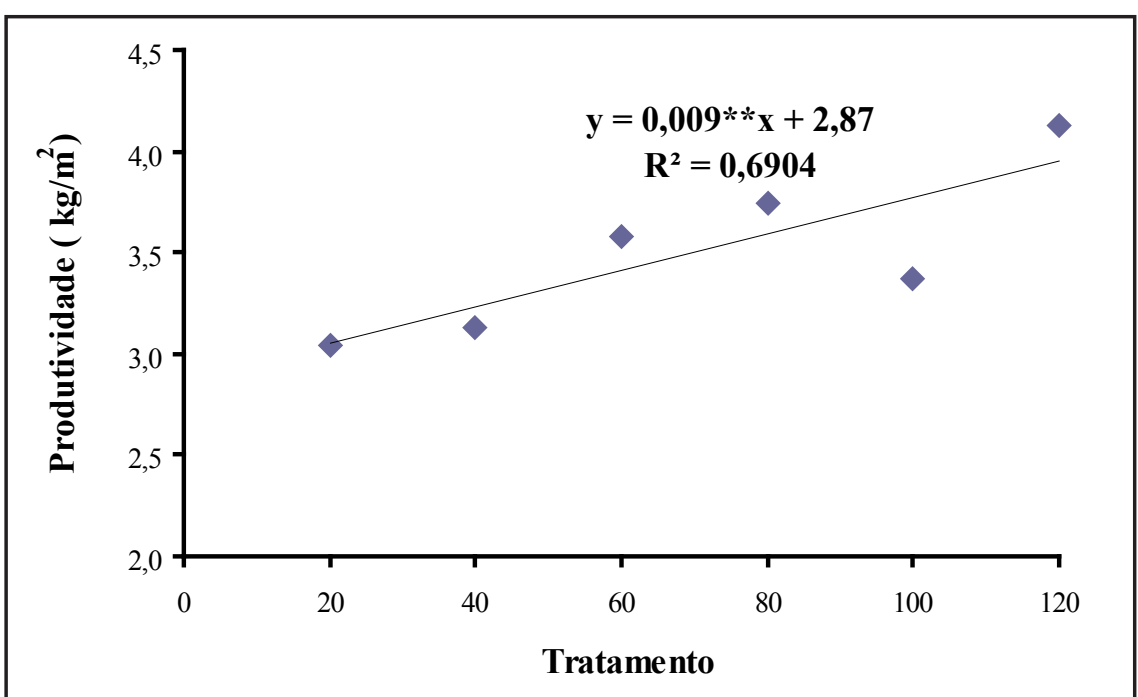

Figura 2. Produtividade $\left(\mathrm{kg} \mathrm{m}^{-2}\right)$ do melão $\mathrm{cv}$. Bônus $\mathrm{n}^{\mathrm{o}} 2$, cultivado em ambiente protegido em função das lâminas de irrigação (commercial yield of muskmelon cultivar Bonus $\mathrm{n}^{\mathrm{o}} 2$ grown under plastic house conditions as function of irrigations levels). Boa Vista-RR, UFRR, 2008. a cada mês durante o período experimental e os valores médios do potencial mátrico do solo podem ser obtidos na Tabela 1. As lâminas totais oscilaram de $161,6 \mathrm{~mm}$ (tratamento 0,2 ) a 374,5 $\mathrm{mm}$ (tratamento 1,2). Segundo Silva \& Costa (2003), a necessidade de água do meloeiro, do plantio à colheita, varia de 300 a $550 \mathrm{~mm}$, dependendo das condições climáticas, sistema de irrigação e cultivar. Os valores médios de potencial mátrico, ao longo do período experimental, resultaram em $-52 \mathrm{kPa} ;-38 \mathrm{kPa}$; $-28 \mathrm{kPa} ;-43 \mathrm{kPa} ;-10 \mathrm{kPa}$ e $-21 \mathrm{kPa}$ para os tratamentos 0,$2 ; 0,4 ; 0,6 ; 0,8 ; 1,0 \mathrm{e}$ 1,2 respectivamente. Braga et al. (2006), em estudo sobre o cultivo de melão em estufa, concluíram que o potencial mínimo de água no solo de -30 a $-40 \mathrm{kPa}$ pode ser utilizado como critério de início da irrigação para obtenção de maiores produções de melão.

A massa fresca individual do fruto e a produtividade foram influenciadas positivamente pelas lâminas de irrigação, aumentando linearmente com o aumento das lâminas (Figuras 1 e 2).

A massa fresca de frutos variou entre $761,9 \mathrm{~g}$ e $1.033,8 \mathrm{~g}$, as quais foram obtidas com as aplicações de 161,6 e $374,5 \mathrm{~mm} \mathrm{ciclo}^{-1}$, respectivamente. Tais valores mostraram-se numericamente superiores ao obtido por Rizzo \& Braz (2001), quando a massa do melão cv. Bônus $\mathrm{n}^{\circ} 2$ cultivado em ambiente protegido foi de 693,3 $\mathrm{g}$.

A produtividade variou entre 3,05 e $3,95 \mathrm{~kg} \mathrm{~m}^{-2}$, obtidas com os tratamentos 0,2 e $1,2 \%$ do ECA e a aplicação de 161,6 e $374,5 \mathrm{~mm} \mathrm{ciclo}^{-1}$, respectivamente. Esses valores foram similares aos obtidos por Koetz et al. (2006), onde a máxima produção de melão amarelo cv. Cantaloupensis, cultivado em ambiente protegido, foi verificada com o uso de irrigação correspondente a 1,25 do ECA. Os autores verificaram produtividade de $28,49\left(2,8 \mathrm{~kg} \mathrm{~m}^{-2}\right)$ a $40,23 \mathrm{t} \mathrm{ha}^{-1}\left(4 \mathrm{~kg} \mathrm{~m}^{-2}\right)$, dependendo da lâmina de irrigação utilizada; porém, estatisticamente, não houve diferença significativa entre os tratamentos. Em campo, Costa et al.(2002), trabalhando com três lâminas de irrigação, também verificaram efeito linear sobre a produção de melão Cantaloupe. Também Monteiro (2004) verificou uma relação 


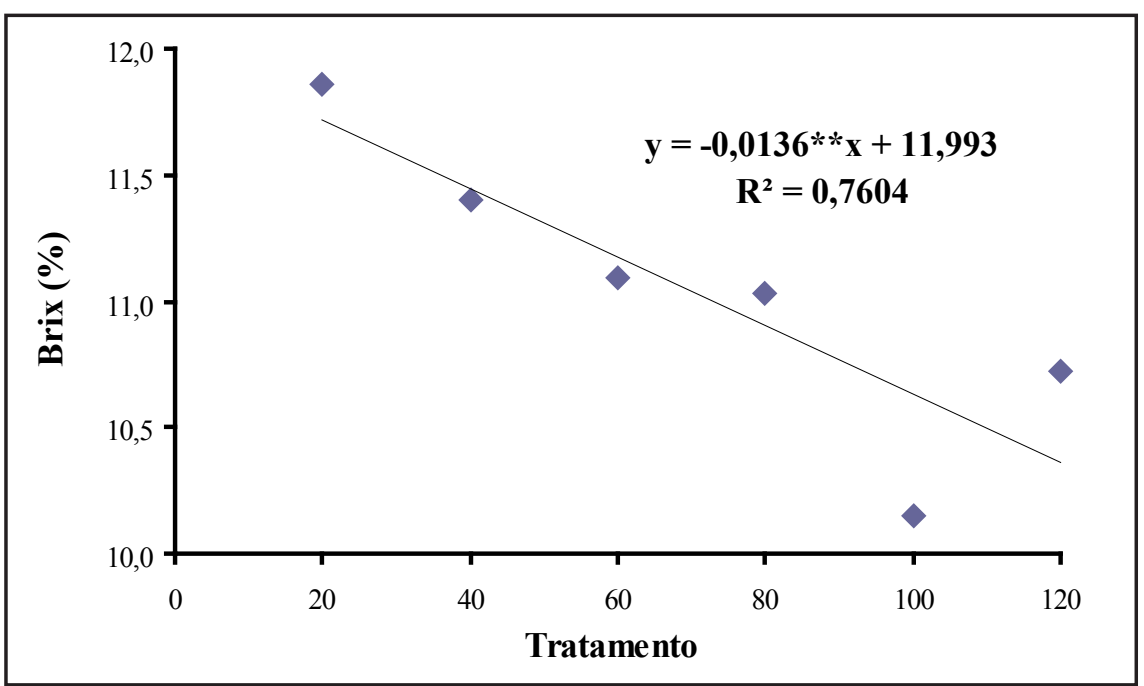

Figura 3. Valor de ${ }^{0}$ Brix do melão cv. Bônus n ${ }^{\circ}$ 2, cultivado em ambiente protegido em função das lâminas de irrigação ( ${ }^{0}$ Brix value of muskmelon cultivar Bonus $\mathrm{n}^{\circ} 2$ grown under plastic house conditions as function of irrigations levels ). Boa Vista-RR, UFRR, 2008.

linear entre a produtividade do melão e as lâminas de irrigação. Contrariamente, Dogan et al. (2008) observaram efeito quadrático na produção de melão em função dos níveis de irrigação, aplicados também com base em percentuais do tanque classe $\mathrm{A}$ em dois anos de estudo. Os autores obtiveram produtividade de $8.2 \mathrm{t} \mathrm{ha}^{-1}\left(0,82 \mathrm{~kg} \mathrm{~m}^{-2}\right)$ a $38.9 \mathrm{t} \mathrm{ha}^{-1}(4$ $\left.\mathrm{kg} \mathrm{m}^{-2}\right)$. Rizzo \& Braz (2001) obtiveram produtividade do melão $\mathrm{cv}$. Bônus $\mathrm{n}^{\circ}$ 2 cultivado em ambiente protegido de $13,15 \mathrm{~kg} \mathrm{~m}^{-2}$, quantidade superior à obtida no presente experimento.

A firmeza da polpa dos frutos não foi afetada pelas lâminas de irrigação, obtendo-se um valor médio de $50,75 \mathrm{~N}$ para esta variável. Resultados similares foram encontrados por Hartz (1997) que não observou diferença significativa na firmeza da polpa do melão quando irrigado por gotejamento.

O teor de sólidos solúveis no extrato da polpa do melão foi influenciado pelas lâminas de irrigação, decrescendo linearmente com o aumento das lâminas de irrigação, obtendo os valores máximo e mínimo de 11,72 e $10,36{ }^{\circ}$ Brix, respectivamente (Figura 3). Isso ocorreu provavelmente, devido à redução na concentração dos elementos formadores de açúcares em razão da maior disponibilidade de água na planta e, portanto, nos frutos. Entretanto, todos os valores observados foram superiores a $10^{\circ}$ Brix, portanto, o melão mostrou-se pois supera a média nacional de $6,33 \mathrm{t}$ ha $^{-1}$ (Silva \& Costa, 2003), demonstrando a viabilidade técnica do cultivo do melão em ambiente protegido com o uso da irrigação, sob as condições edafoclimáticas de Boa Vista, Roraima.

\section{AGRADECIMENTOS}

À FEMACT e ao CNPq pelo financiamento da pesquisa; ao $\mathrm{CNPq}$ pela concessão das Bolsas de Iniciação Científica e de Mestrado; à CAPES pelo apoio a pós-graduação em Agronomia da UFRR; ao PIBIC pela concessão da bolsa.

\section{REFERÊNCIAS}

BLEINROTH EW 1994. Determinação do ponto de colheita. In: NETTO AG Melão para exportação: procedimentos de colheita e póscolheita. Brasília: MAARA/FRUPEX. 37p. (FRUPEX, Publicações Técnicas, 6).

BRAGA MBB; DUENHAS LH; SOUZA CM.P; KLAR AE. 2006. Orientação geográfica de estufas de polietileno e potenciais de água no solo no cultivo do melão rendilhado híbrido 'nero'. Irriga 11: 130-138.

BRANDÃO FILHO JUT; VASCONCELLOS MAS. 1998. A cultura do meloeiro. In: GOTO R; TIVELLI SW. (org). Produção de hortaliças em ambiente protegido: condições subtropicais. São Paulo: FUNEP, 161-193.

CASTOLDI R; CHARLO HCO; VARGAS PF; BRAZ LT. 2008. Qualidade de frutos de cinco híbridos de melão rendilhado em função do número de frutos por planta. Revista Brasileira de Fruticultura 30: 455-458.

COELHO EL; FONTES PCR; FINGER FL; CARDOSO AA. 2003. Qualidade do fruto de melão rendilhado em função de doses de nitrogênio. Bragantia 62: 173-178.

COELHO RD. 1978. Influência dos métodos de irrigação por sulco e gotejo na cultura do melão. In: Congresso Brasileiro de Irrigação e Drenagem, 4, 1978, Salvador. Resumos... Salvador: ABID.

COSTA FA; MEDEIROS JF; NEGREIROS MZ; BEZERRA NETO F; PORTO DRQ; CHAVES SW; DANTAS KN. 2002. Rendimento de melão Cantaloupe em diferentes coberturas de solo e lâminas de irrigação. Caatinga 15: 49-55.

DOGAN E; KIRNAK EH; BEREKATOGLU EK; BILGEL EL; SURUCU EA. 2008. Water stress imposed on muskmelon (Cucumis melo L.) with subsurface and surface drip irrigation systems under semi-arid climatic conditions. Irrigation Science 26: 131-138.

GUALBERTO R; RESENDE FV; LOSASSO PHL. 2001. Produtividade e qualidade do melão rendilhado em ambiente protegido, em função do espaçamento e sistema de condução. Horticultura Brasileira 19: 370-376. 
HARTZ TK. 1997. Effects of drip irrigation scheduling on muskmelon yield and quality. Scientia Horticulturae 69: 117-122.

KOETZ M; COELHOG; CARVALHO JA; SOUZA RJ; SILVA RA. 2006. Produção do meloeiro em ambiente protegido irrigado com diferentes lâminas de água. Irriga 11: 500-506.

MENEZES JB; CHITARRA AB; CHITARRA MIF; BICALHO UO. 1998. Caracterização do melão tipo Gália durante a maturação. Horticultura Brasileira 16: 123-127.

MENEZES JB; GOMES JUNIOR J; NUNES GH; COSTA FB; SOUZA PE. 2001. Qualidade pós-colheita de melão tipo Cantaloupe, colhido em dois estádios de maturação. Horticultura Brasileira 19: 356-360.
MONTEIRO ROC. 2004. Função de resposta da cultura do meloeiro aos níveis de água e adubação nitrogenada no vale do Curu, CE. Fortaleza: UFC. 92p (Tese mestrado).

PADUAN MET; CAMPUS RP; CLEMENTE E. 2007. Qualidade dos frutos de tipos de melão, produzidos em ambiente protegido. Revista Brasileira de Fruticultura 29: 535-539.

RAIJ BV; CANTARELLA H;QUAGGIO JA; FURLANI AMC. 1997. Recomendações de adubações e calagem para o Estado de São Paulo. Campinas, Instituto Agronômico. 279p. (Boletim Técnico, 100).

RIZZO AAN; BRAZ LT. 2001. Características de cultivares de melão rendilhado cultivadas em casa de vegetação. Horticultura Brasileira 19: 237-240.
SILVA HR; COSTA ND. (ed) 2003. Melão Produção Aspectos Técnicos. Brasília: Embrapa Hortaliças/Embrapa Semi-Árido/ Embrapa Informação Tecnológica. 144p (Frutas do Brasil, 33).

SIQUEIRA WC; FARIA LA; LIMA EMC; REZENDE FC; GOMES LAA; CUSTÓDIO TN. 2009. Qualidade de frutos de melão amarelo cultivado em casa de vegetação sob diferentes lâminas de irrigação. Ciência agrotecnológica 33: 1041-1046.

VENTURA Y; MENDLINGER S. 1999. Effect of sub optimal low temperature on yield, fruit appearance and quality in muskmelon (Cucumis melo L.) cultivars. Journal of Horticultural Science \& Biotechnology 74: 602-607. 